American Journal of Infectious Diseases 4 (2): 156-161, 2008

ISSN 1553-6203

(C) 2008 Science Publications

\title{
Identification of Methicillin Resistant Staphylococcus aureus (MRSA) and Methicillin Resistant Coagulase-Negative Staphylococcus (CoNS) in Clinical Settings
}

\author{
${ }^{1}$ Shorman, M.A., ${ }^{2}$ Atoom, A.M., N. M. ${ }^{3}$ Abuharfeil, N.M. and ${ }^{4}$ Al-Majali, A.M. \\ ${ }^{1}$ Department of Internal Medicine and the Infection Control Unit, King Abdallah Hospital, Jordan \\ University of Science and Technology, Irbid, Jordan \\ ${ }^{2}$ Department of Laboratory Medical Science, Jordan University of Science and Technology, Irbid, Jordan \\ ${ }^{3}$ Department of Biotechnology, Jordan University of Science and Technology, Irbid, Jordan \\ ${ }^{4}$ Department of Veterinary Clinical Sciences, Jordan University of Science and Technology, Irbid, Jordan
}

\begin{abstract}
To evaluate different methods for the identification of methicillin-resistant Staphylococci and their reliability, 112 Staphylococcal isolates (32 Staphylococcus aureus isolates and 80 coagulase negative Staphylococci isolates "CoNS") were collected from 118 nasal swab cultures and were subjected to three methods to detect oxacillin susceptibility of the isolates. The three methods were oxacillin disk diffusion method; the Epsilometer- test (E-test) and polymerase chain reaction (PCR). For the $S$. aureus strains, the E-test and the PCR methods showed discrepant results in two isolates $(6.25 \%)$; that showed susceptible patterns with the E-test, but were resistant by the disk diffusion method. Both isolates were negative for the presence of mecA gene. Seven $(8.75 \%)$ out of the 80 CoNS isolates showed conflicting results where four isolates showed resistance with the disk diffusion and the E-test methods, and had negative mecA gene by PCR. Three of the 7 CoNS with the conflicting results showed a susceptible pattern to oxacillin by the E-test method, while the PCR method showed the presence of mecA gene. We concluded that combination of molecular and conventional methods should be used to assess methicillin resistance of Staphylococci in clinical practices.
\end{abstract}

Key words: Methicillin, Resistance; Clinical

\section{INTRODUCTION}

The incidence of infections caused by methicillin resistant Staphylococcus aureus (MRSA) is increasing which require rapid and accurate detection ${ }^{[1,}$ ${ }^{2]}$. Diseases due to Staphylococcus aureus include infections affecting the skin, bone infections (osteomyelitis), prosthetic devices related infections, and even life threatening infections including bacteremia, endocarditis with remote complications ${ }^{[3]}$. Coagulase- negative staphylococci (CoNS) are considered among the most isolated bacteria in clinical microbiology laboratory. Their importance as pathogens is established as hospital acquired infections, especially in debilitated patients ${ }^{[4]}$.

Methicillin-resistant Staphylococcus aureus (MRSA) are bacteria that are resistance to penicillinasestable semisynthetic penicillins such as Methicillin, Nafcillin, Oxacillin and Cloxacillin. The mecA gene encodes this type of resistance and expression of this gene results in production of a penicillin binding protein $(\mathrm{PBP} 2 \mathrm{a})$. This binding protein has low affinity to methicillin making bacteria that produce it resistant to all $\beta$-lactam antibiotics, and even to other antibiotics from other classes, including tetracyclines, macrolides, flouroquinolones. Infections with MRSA are more serious than other organisms as the available treatment options are limited; and there is already described resistance to these treatment options such as the described cases of vancomycin resistant Staphylococcus aureus $^{[5]}$. The MRSA infections were usually encountered in health-care settings and more cases of MRSA infections were described as being community acquired $^{[8]}$. Therefore, proper and prompt diagnosis of MRSA isolates will result in proper treatement and control measures ${ }^{[9]}$.

Resistance in CoNS is attributed to the same mechanisms as in Staphylococcus aureus and mecA

Corresponding Author: Ahmad M. Al-Majali, Head, Dept. of Veterinary Clinical Sciences, School of Veterinary Medicine, Texas Tech University, Jordan University of Science and Technology, P. O. Box 3030, Irbid 22110, Jordan. Tel: 962-2-7201000 Ext. 22018, Fax: 962-2-7201081 
gene when present is expressed at a lower level than MRSA making its detection more difficult. ${ }^{10}$

Several risk factors for acquisition of MRSA have been identified. Hospitalizations, admission to intensive care units, having surgical wounds or being intravenously catheterized were found to be correlated to acquiring MRSA infections. A prolonged hospital stay, and prior exposure to broad-spectrum antimicrobial therapy also appear to be an important predisposing factor for MRSA colonization ${ }^{[7,11,12-13]}$.

Our study was designed to assess the reliability of some of the different available methods used in clinical practice for identifying MRSA and resistant CoNS.

\section{MATERIALS AND METHODS}

Sample collection: This investigation was carried out at King Abdullah University Hospital (KAUH), during the period between February to July 2004. Onehundred-eighteen nasal swabs were collected from health care workers (77 males and 41 females) aged between 23-40 years. Nasal swabs were saturated with sterile normal saline, and then rotated in the anterior nares. Collected swabs were cultured on mannitol salt agar (Difco, Detroit, MI, USA) and then incubated at $35^{\circ} \mathrm{C}$ for 48 hours. The cultures were then characterized, and sub-cultured for the mixed colonies, coagulase test was performed for all the isolates. Bacterial identification were performed following standard procedures.

Oxacillin disk diffusion: The isolated Staphylococcus strains were tested for their susceptibilities to oxacillin and other antibiotics following previously reported method $^{[14]}$. Briefly, isolates were spread on MuellerHinton Agar (Difco, Detroit, MI, USA) plates supplemented with $4 \% \mathrm{NaCl}$. Plates were then inverted and incubated for 18 hours at $35^{\circ} \mathrm{C}$. To obtain the best results, the agar plates had no excess moisture and the antibiotic disks containing $1 \mu \mathrm{g}$ (including oxacillin) (Oxoid Ltd, Basingstoke, England) were brought to room temperature before use, and the distance between the disks was at least two centimeters. The diameter of the inhibition zones was measured and results were then reported according to the National Committee for Clinical Laboratory Standards (NCCLS) guidelines ${ }^{15}$.

E- test Method: The E-test (PDM- Epsilometer, AB Biodisk, Solona, Sweden) was used to measure the individual minimal inhibitory concentrations (MICs) according to the NCCLS guidelines. Mueller-Hinton Agar (Difco, Detroit, MI, USA) supplemented with 2\% $\mathrm{NaCl}$ was used for this purpose. Samples for the E-test was prepared according to Novak et $\mathrm{al}^{[16]}$.

Polymerase chain reaction (PCR) for Identification of $\boldsymbol{m e c A}$ Gene: This method was done according to Smyth et $\mathrm{al}^{[17,18]}$. Briefly, Nucleotides primers were purchased from Alpha DNA, Montereal, Canada. Primers $m e c A-1,5^{\prime}$-GCA ATC GCT AAA GAA CTA AG and $m e c A-2$ 5'-GGG ACC AAC ATA ACC TAA TA were derived from the gene mecA BB270 (EMBL data base). From the agar plate, 5 colonies were picked and suspended in $100 \mu \mathrm{L}$ sterile water. Bacterial suspensions were run for 15 minutes at $98^{\circ} \mathrm{C}$ in a DNA thermocycler (Mycycler, Biorad, USA) and cell debris were removed by centrifugation (13,000 rpm for 30s). The supernatant was used as DNA template for the PCR amplification. Two $\mu \mathrm{L}$ of DNA was added to 18 $\mu \mathrm{L}$ of chilled PCR mixture containing $10 \mathrm{mM}$ Tris $(\mathrm{pH}$ 8.3), $5 \mathrm{mM} \mathrm{MgCL}_{2}, 0.2 \mathrm{mM} \mathrm{dNTP}, 0.5 \mu \mathrm{M}$ of each primer and $0.5 \mathrm{U}$ Ampli Taq DNA polymerase. The following amplification protocol was used: denaturation at $94{ }^{\circ} \mathrm{C}$ for $3 \mathrm{~min}$, annealing at $53^{\circ} \mathrm{C}$ for $2 \mathrm{~min}$, and extension at $72{ }^{\circ} \mathrm{C}$ for $5 \mathrm{~min}$ for 30 cycles to completion. The final cycle conisited of extension at $72^{\circ} \mathrm{C}$ for $7 \mathrm{~min}$. PCR products were detected by electrophoresis on a 3\% agarose-Tris-borate-EDTA gel (Nusieve Bioproducts, Maine). After electrophoresis the gel was stained with ethidium bromide and photographed under UV light (Fig. 1). The results were reported as negative or positive.

\section{RESULTS}

Disk Diffusion Method: The percentage of oxacillin resistance among all samples was $66.9 \%$ (75 isolates), and the resistance percentages for other antibiotics was: Lincomycin 61.6\% (69 isolates), Erythromycin 66.9\% (75 isolates), Gentamicin $73.2 \%$ (82 isolates), Augmentin $72.3 \%$ (81 isolates), and Cephalothin 66.9\% (75 isolates) (Table I).

The susceptibility patterns among the eightycoagulase negative samples were as follow: 69 isolates (86.2\%) were resistant to Oxacillin and the other 11 isolates $(13.8 \%)$ were susceptible. 
Table1: Antimicrobial Susceptibility patterns among coagulase positive and coagulase negative isolates as measured by disk diffusion method.

\begin{tabular}{cccccccccc}
\hline & \multicolumn{3}{c}{ Coagulase positive } & \multicolumn{3}{c}{ Coagulase negative } & \multicolumn{2}{c}{ General for all isolates } \\
\cline { 2 - 9 } Antibiotics & $\mathrm{S}$ & $\mathrm{I}$ & $\mathrm{R}$ & $\mathrm{S}$ & $\mathrm{I}$ & $\mathrm{R}$ & $\mathrm{S}$ & $\mathrm{I}$ & $\mathrm{R}$ \\
& No. $(\%)$ & No. $(\%)$ & No. $(\%)$ & No. $(\%)$ & No. & No. $(\%)$ & No. $(\%)$ & $\begin{array}{c}\text { No. } \\
(\%)\end{array}$ & No. $(\%)$ \\
& & & & & & & & $(\%)$ & \\
\hline Oxacillin & 25 & 1 & 6 & 11 & - & 69 & 36 & 1 & 75 \\
& $(78.1)$ & $(3.1)$ & $(18.8)$ & $(13.8)$ & & $(86.2)$ & $(32.2)$ & $(0.9)$ & $(66.9)$ \\
Cephalothi & 27 & - & 5 & 10 & - & 70 & 37 & - & 75 \\
$\mathrm{n}$ & $(84.4)$ & & $(15.6)$ & $(12.5)$ & & $(87.5)$ & $(33.0)$ & & $(66.9)$ \\
Gentamyci & 20 & - & 12 & 10 & - & 70 & 30 & - & 82 \\
$\mathrm{n}$ & $(62.5)$ & & $(37.5)$ & $(12.5)$ & & $(87.5)$ & $(26.8)$ & & $(73.2)$ \\
Augmentin & 22 & - & 10 & 9 & - & 71 & 31 & - & 81 \\
& $(68.8)$ & & $(31.2)$ & $(11.2)$ & & $(88.8)$ & $(27.7)$ & & $(72.3)$ \\
Erythromy & 17 & - & 15 & 11 & - & 69 & 37 & - & 75 \\
cin & $53.1)$ & & $(46.9)$ & $(13.8)$ & & $(86.2)$ & $(33.1)$ & & $(66.9)$ \\
Vancomyci & 32 & - & - & 80 & - & - & 112 & - & - \\
$\mathrm{n}$ & $(100)$ & & & $(100)$ & & & $(100)$ & 2 & 69 \\
Lincomyci & 16 & 1 & 15 & 25 & 1 & 54 & 41 & 2 \\
$\mathrm{n}$ & $(50)$ & $(3.1)$ & $(46.9)$ & $(31.2)$ & $(1.3)$ & $(67.5)$ & $(36.6)$ & $(1.8)$ & $(61.6)$ \\
\hline
\end{tabular}

S: sensitive; I: intermediate; C: resistant

For coagulase positive isolates, disk diffusion method showed only 6 isolates $(18.8 \%)$ resistant to Oxacillin and to all other antibiotics, making these isolates MRSA. On the other hand, 25 isolates (78.1\%) were susceptible to Oxacillin, while only one sample $(3.1 \%)$ had intermediate resistance to Oxacillin. All one hundred and twelve staphylococcal isolates $(100 \%)$ were susceptible to Vancomycin (Table I)

E test method: The E-test method was carried out for all the thirty-two coagulase positive Staphylococcal isolates, and for the 80-coagulase negative isolates. Only five $(15.6 \%)$ of the coagulase positive isolates were resistant to Oxacillin (having an MIC value equal to, or more than $4 \mu \mathrm{g} / \mathrm{ml}$ ), the remaining twenty-seven isolates $(84.4 \%)$ were susceptible to Oxacillin with MIC value less or equal to $2 \mu \mathrm{g} / \mathrm{ml}$.

For the coagulase negative isolates, $69(86.2 \%)$ were resistant to Oxacillin with MIC value equal to or more than $0.5 \mu \mathrm{g} / \mathrm{ml}$ and $11(13.8 \%)$ isolates were susceptible to Oxacillin with MIC value less or equal to $0.25 \mu \mathrm{g} / \mathrm{ml}$.
Table 2: Coagulase negative strains for which the disk diffusion, E-test, and mecA PCR gave discrepant results.

\begin{tabular}{cccccc}
\hline \multirow{2}{*}{$\begin{array}{c}\text { No. Of } \\
\text { Isolate }\end{array}$} & \multicolumn{2}{c}{ Disk } & \multicolumn{2}{c}{ E- test } & \\
\cline { 2 - 5 } & $\begin{array}{c}\text { donfusion } \\
(\mathbf{m m})\end{array}$ & Susc. & $\begin{array}{c}\text { MICs } \\
(\boldsymbol{\mu g} / \mathbf{m l})\end{array}$ & Susc. & PCR \\
\hline 3 & 20 & $\mathrm{~S}$ & 0.25 & $\mathrm{~S}$ & + \\
6 & 19 & $\mathrm{~S}$ & 0.25 & $\mathrm{~S}$ & + \\
9 & 15 & $\mathrm{R}$ & 1.0 & $\mathrm{R}$ & - \\
31 & 14 & $\mathrm{R}$ & 0.5 & $\mathrm{R}$ & - \\
44 & 14 & $\mathrm{R}$ & 1.5 & $\mathrm{R}$ & - \\
60 & 13 & $\mathrm{R}$ & 3.0 & $\mathrm{R}$ & - \\
80 & 20 & $\mathrm{~S}$ & 0.25 & $\mathrm{~S}$ & + \\
\hline
\end{tabular}

Susc.: Susceptibility; S; susceptible, R; resistant

\section{PCR Method:}

The results of PCR indicated that 5 isolates of the coagulase positive Staphylococcal isolates (15.6\%) were positive for the presence of mecA gene, and the remaining 27 isolates $(84.4 \%)$ were negative for $m e c A$ gene. For coagulase negative isolates, 68 $(85.0 \%)$ were positive for the presence of $m e c A$ gene and the other $12(15.0 \%)$ isolates were negative. Two 


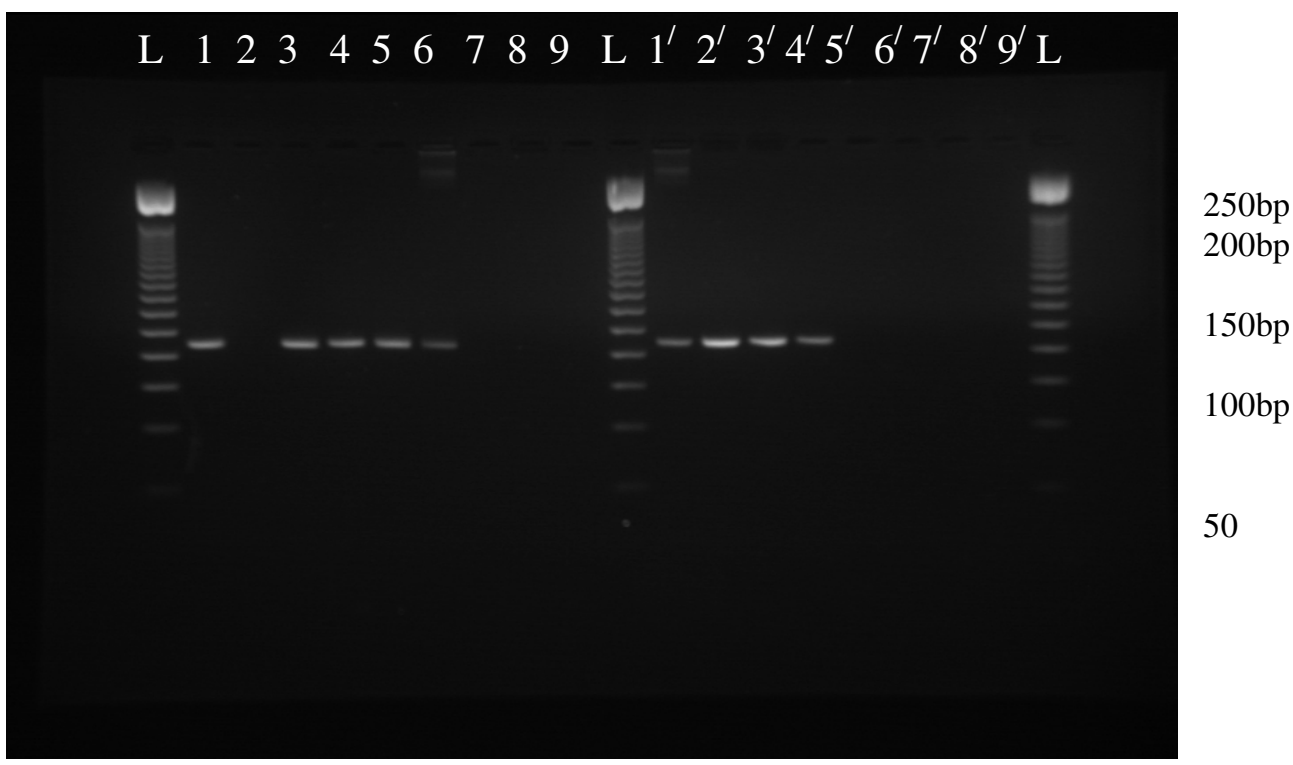

Fig. 1: Agarose Gel Electrophoresis of PCR for mecA Gene Presence. (L: 50bp DNA ladder, 1: MRSA positive control, 2: negative control, 3-6: coagulase positive MRSA (positive mecA gene), 7-9: coagulase positive MSSA (negative mecA gene). $1^{\prime}-4^{\prime}$ : coagulase negative oxacillin resistant (positive mecA gene), $5^{\prime}-9^{\prime}$ : coagulase negative oxacillin susceptible (negative $m e c A$ gene)).

coagulase positive isolates and seven coagulase negative isolates showed discrepant results between disk diffusion, E-test and mecA PCR methods. The discrepant results between the three methods are shown in Tables 2, 3 .

Table 3: Staphylococcus aureus strains for which the disk diffusion, E-test, and mecA PCR gave discrepant results.

\begin{tabular}{cccccc}
\hline \multirow{2}{*}{$\begin{array}{c}\text { No. Of } \\
\text { Isolate }\end{array}$} & \multicolumn{2}{c}{ Disk } & \multicolumn{2}{c}{ E- test } & \\
\cline { 2 - 5 } & $\begin{array}{c}\text { diffusion } \\
(\mathbf{m m})\end{array}$ & Susc & $\begin{array}{c}\text { MICs } \\
(\boldsymbol{\mu g} / \mathbf{m l})\end{array}$ & Susc. & PCR \\
\hline 1 & 12 & $\mathrm{I}$ & 0.50 & $\mathrm{~S}$ & - \\
67 & 0 & $\mathrm{R}$ & 1.50 & $\mathrm{~S}$ & - \\
\hline
\end{tabular}

S: sensitive; I: intermediate; R: resistant

\section{DISCUSSION}

Staphylococcus aureus is one of the most important nosocomial pathogens, and now coagulase- negative staphylococcus (CoNS) is also recognized as an important cause of nosocomial infections. Staphylococci accounted for about fifty percent of blood stream infections in intensive care units according to the National Nosocomial Infections
Surveillance System data between 1990-1999 ${ }^{[19]}$. The major problem of resistance is increasing for all types of bacteria including the Staphylococci. Resistant $S$. aureus was seen in clinical practice as early as the 1950s, by acquiring a plasmid that encodes the production of $\beta$-lactamase enzymes causing resistance to penicillin. Then a synthetic type of penicillin (methicillin) became available for use in 1959. MRSA was described as early as the 1960 , this was due to the acquisition of the mecA gene, which is responsible for the altered penicillin binding protein PBP2a accounting for MRSA resistance ${ }^{[20]}$. Now glycopeptide resistance has been described in Staphylococci making treatment options more limited and the prognosis worse ${ }^{[21]}$.

Due to the major role of Staphylococcus as a major cause of nosocomial infections, this study was conducted to compare between three methods of Staphylococcal identification to evaluate the best method for rapid screening and detection of methicillin strains, so that health care workers can start their patients on the proper antibiotic therapy as soon as possible.

Among the 118 samples collected from nasal swabs in our study, one hundred and twelve Staphylococcal isolates were obtained, thirty-two $S$. aureus, and eighty isolates of coagulase negative 
staphylococcus (CoNS). The coagulase positive strains $32(27.1 \%)$ showed various susceptibility patterns for different antimicrobial agents with differences depending on the method used, as did the eighty CoNS isolates which showed more Oxacillin resistance. Huebner et al, found that $62-87 \%$ of coagulase negative strains were resistant to Oxacillin, Gentamycin and Trimethoprim ${ }^{[22]}$.

Geary et al showed that most coagulase negative strains are resistant to $\beta$-lactam antibiotics and produce $\beta$-lactamase ${ }^{[23]}$. Wolfgang study showed that the incidence of Methicillin resistance $S$. epidermidis increased from $28 \%$ in 1983 to $77 \%$ in 1994 in Finland $^{[24]}$.

The discrepant results in our study cannot be related to technical problems as these results were confirmed by repeated testing. The discrepancies between the three methods can be in apart explained by the heterogeneous expression of resistance, for example Araj et al, study of thirty-two MRSA isolates initially identified by disk diffusion method, then the PCR method was done and only thirteen isolates were positive for the presence of mecA gene, seven isolates were found to be resistant by the E-test method $^{[25]}$. Felten et al, calculated the sensitivities of different methods used for MRSA detection based on PCR as a standard, he showed that the E-test failed to detect resistance in seven isolates that were positive for the presence of mecA gene ${ }^{[26]}$. Ngui et al, evaluated E-test for detection the resistance in selected gram positive bacteria compared with standard reference methods and found that the accuracy of the Oxacillin E-test with Staphylococci was significantly improved by the use of saltsupplemented Mueller-Hinton agar ${ }^{[27]}$.

There are other mechanisms of resistance in Staphylococci, for example methicillin resistance in mecA negative strains of $S$. aureus can be explained by hyper production of $\beta$-lactamase enzymes, also the production of a normal PBP but with altered binding capacity. The presence of a positive mecA gene doesn't always mean there is Staphylococcal resistance to methicillin as susceptible patterns can be seen with the E-test and disk diffusion methods, this could be explained by the presence of incomplete regulator genes (mecI and/or mecRI), also there are strains that posses mecA gene without being able to express it. ${ }^{25}$ These mechanisms can help explain the discrepant findings among tests in our study.

In conclusion, this study suggest that the current available methods for detecting methicillin resistance for Staphylococci had limitations and that more accurate results may be obtained by combining conventional and molecular methicillin resistance detection methods

\section{REFERENCES}

1. Berger-Bachi, B. 1999. Genetic basis of methicillin resistance in Staphylococcus aureus. Cell. Mol. Life Sci. 56: 764-770.

2. Peters, G. and Becker, K. 1996. Epidemiology, control and treatment of Methicilin resistant Staphylococcus aureus. Drugs 52(Suppl.2): 5054.

3. Jean, C.L. 1996. The prospects for developing a vaccine against staphylococcus aureus. Trends in Microbiol. 4: 162-66.

4. Christof von Eiff, Peters, G. and Heilmann, C. 2002. Pathogenesis of infections due to coagulase-negative staphylococci. Lancet infect. dis. 2: 677-685.

5. Centers for Disease Control (CDC). 2002. Staphylococcus aureus resistant to vancomycinUnited States Mor. Mortal Wkly RP 51: 565-7.

6. Vicki, L.B. and Rhonda, H. 2000. Methicillin resistance Staphylococcus aureus (MRSA): is their need to change clinical practice. Intensive and Critical Care Nurs. 6: 357-66.

7. Hardy, K.G., Hawkey, P.M., Gao, F. and Oppenheim, B.A. 2004. Methicillin resistance Staphylococcus aureus in the critically ill. British J. of Anaesth. 92: 121-130.

8. Goetz, A., Poesy, K., Fleming, J. et al. 1999. Methicillin-resistant Staphylococcus aureus in the community: a hospital based study. Infect. Control and Hosp. Epid 20:689-91.

9. Ayliffe, A.G., Kasewell, M.W., Cox, R.A., Duckworth, G.J., Heathcock, R., Keane, C.T., Shanson, D.C., Slack, R. and Tebbs, E. 1998. Revised guidelines for the control of the Methicillin resistant Staphylococcus aureus infection in hospital. J. Hos. Infec. 39: 253-90.

10. Livermore, D.M. 2000. Antibiotic Resistance in Staphylococci. Intl J.Antimicrob. Agents 16; S3S10.

11. Thompson, R.L., Cabezudo, I. and Wenzel, R.P. 1982. Epidemiology of nosocomial infections caused by methicillin-resistant Staphylococcus aureus. Ann. Intern. Med. 97:309-17.

12. Henery, F.C. 2001. The changing epidemiology of Staphylococcus aureus. Emerg. Infect. dis.7: 178-82.13.

13. Boyce, J.M. 1989. Methicillin- resistant Staphylococcus aureus: detection, epidemiology, and control measures. Infect. Dis. Clin. North Am. 3:901-13. 
14. Isenberg, D.H. 1992. Clinical microbiology, procedure hand book volum1. Library of congress cataloging in publication data.

15. National Committee for Clinical Laboratory Standards. 2000. Performance standards for antimicrobial susceptibility testing, $7^{\text {th }}$ edition. Approved standard M2-A7. National Committee for Clinical Laboratory Standards. Wayne, PA.

16. Novak, S.M., Hindler, J. and Bruckner, D.A. 1993. Reliability of two novel methods, Alamar and E-test, for detection of methicillin-resistant staphylococcus aureus. J. Clin. Microbiol. 31:3056-7.

17. Smyth, R.W., Kahlmeter, G., Olsson, B.L. and Hoffman, B. 2001. Methods for identifying methicillin resistance in Staphylococcus aureus. J. Hos. Infect. 48: 103-07.

18. Promega cooperation. Technical manual genomic DNA purification part TM0580. USA: Madison; 2004: 12.

19. National Nosocomial Infections Surveillance (NNIS) system report: 1999. Data summary from January 1990- May 1999. Am. J. Infect. Control 27:520-32.

20. Shopsin, B.O. and Barry, N.K. 2001. Molecular epidemiology of methicillin resistance Staphylococcus aureus. Emer. Infec. Dis. 7: 32326.

21. Keiichi, H. 1998. The emergence of Staphylococcus aureus with reduced susceptibility of vancomycin in Japan. Am. J. Med 104: 7S-9S.
22. Huebner, J,, Pier, G,B. Maslow, J.N., Muller, E., Shire, H., Parent, M., Kropec, A., Arbeit, R.D. and Glodmann, A. 1994. Endemic nosocomial transmission of Staphylococcus epidermidis bacteremia isolates in a neonatal intensive care unit over 10 years. J. Infect. Dis. 169: 526-31.

23. Geary, C., Jordens, J.Z., Richardson, J.F., Hawcpoft, D.M. and Mitchell, C.J. 1997. Epidemiological typing of coagulase negative staphylococci from nosocomial infection. J. Med. Microbiol. 4: 195-203.

24. Wolfgang, W. 1999. Antibiotic resistance in gram positive bacteria: epidemiological aspect. J. Antimicrob. Chemother. 44: Topic A, 1-9.

25. Araj, G.F., Talhouk, R.S., Simaan, C.J. and Maasad, M.J. 1999. Discrepancies between mecA PCR and conventional tests used for detection of MRSA. Inter. J. Antimicrobial Agents 11: 47-52.

26. Annie, F., Bernadette, G., Philippe, H.L. and Isabelle, C. 2002. Evaluation of the three techniques for detection of low level MRSA: a disk diffusion method with cefoxitin and moxalactam, the Vitek 2 system and the MRSAscreen latex agglutination test. J. Clin. Microbiol. 40 2766-71.

27. Ngui, Y.J., Bryce, E.A., Porter, C. and Smith, J.A. 1992. Evaluation of the E-test by using selected gram- positive bacteria. J. Clin. Microbiol. 30: 2150. 